\title{
Degradation of chlorophenoxyacetic acids by the lignin-degrading fungus Dichomitus squalens
}

\author{
G. Vijay Bhasker Reddy, Dinesh K. Joshi and Michael H. Gold \\ Author for correspondence: Michael H. Gold. Tel: +1 503690 1076. Fax: +1 5036901464 . \\ e-mail: mgold@admin.ogi.edu
}

Department of

Biochemistry and Molecular Biology, Oregon Graduate Institute of Science and Technology, PO Box 91000 Portland, OR 97291-1000, USA
We have examined the degradation of ${ }^{14} \mathrm{C}$ ring- and side-chain-labelled 2,4,5trichlorophenoxyacetic acid by Dichomitus squalens and Phanerochaete chrysosporium. The effects of $\mathrm{Mn}^{2+}$ on the degradation of these radiolabelled substrates by $D$. squalens and the effect of nitrogen limitation on their degradation by $P$. chrysosporium suggested that in both fungi, side-chain cleavage was catalysed by a mechanism independent of the lignin degradation system, whereas the degradation of the aromatic ring was dependent on the lignin degradative system. Using unlabelled substrates, a pathway for the degradation of chlorophenoxyacetic acids was elucidated in $D$. squalens. Time courses for the degradation of unlabelled chlorophenoxyacetic acids by $D$. squalens demonstrated that the corresponding chlorophenol was the initial product formed. The chlorophenol intermediate was xylosylated to form the chlorophenolxyloside. In turn, the chlorophenolxyloside could be hydrolysed by an intracellular $\beta$-xylosidase to regenerate the chlorophenol. The chlorophenol product of the xylosidase reaction was oxidatively dechlorinated to form 2-chloro-p-benzoquinone which could undergo subsequent further dechlorination and ring-opening reactions, as has been reported previously for P. chrysosporium.

Keywords: chlorophenoxyacetic acids, chlorophenols, chlorophenol xyloside, white-rot fungi, $p$-benzoquinone.

\section{INTRODUCTION}

Chlorinated phenoxyacetic acids, such as 2,4dichlorophenoxyacetic acid (2,4-D) and 2,4,5trichlorophenoxyacetic acid $(2,4,5-\mathrm{T})$, have been used as herbicides, plant growth regulators, and defoliants (Loos, 1975). The current annual US consumption of 2,4-D is approximately 20000 tons (Hileman, 1996), and the extensive use of these compounds is recognized as an environmental and toxicological hazard. Chlorophenoxyacetic acids are teratogenic and mutagenic (Grant, 1979) and cause a variety of adverse neurological symptoms (Elo et al., 1988; Oliveira \& Palermo-Neto, 1993). Furthermore, chlorophenoxyacetic acids suppress the immune system, thereby

Abbreviations: 2,4-D, 2,4-dichlorophenoxyacetic acid; 2,4-DCP, 2,4dichlorophenol; 2,4-DCPX, 2,4-dichlorophenol xyloside; 2,4,5-T, 2,4,5trichlorophenoxyacetic acid; 2,4,5-TCP, 2,4,5-trichlorophenol; 4-C, 4chlorophenoxyacetic acid; 4-CP, 4-chlorophenol; 4-CPX, 4-chlorophenol xyloside; LiP, lignin peroxidase; MnP, manganese peroxidase. increasing the vulnerability of mammals to infectious diseases and cancers (Hileman, 1996).

Bacterial degradation of 2,4-D and 2,4,5-T in pure and mixed cultures has been reported (Kilbane et al., 1982; Sinton et al., 1986; Pieper et al., 1988; Haugland et al., 1990), as has the microbial biodegradation of 2,4,5-T in soils (McCall et al., 1981). Although bacterial biodegradation pathways for 2,4-D and 2,4,5-T have been studied (Sinton et al., 1986), much less is known about the fungal degradation of these pollutants. Whiterot basidiomycetous fungi are primarily responsible for the initial depolymerization of lignin during wood decay (Kirk \& Farrell, 1987; Higuchi, 1990; Gold \& Alic, 1993). When cultured under ligninolytic conditions, Phanerochaete chrysosporium, the best-studied whiterot basidiomycete, produces two types of extracellular haem peroxidases - manganese peroxidase $(\mathrm{MnP})$ and lignin peroxidase $(\mathrm{LiP})$ - which, together with an $\mathrm{H}_{2} \mathrm{O}_{2}$ generating system, constitute the major extracellular components of its lignin-degrading system (Buswell \& 
Odier, 1987; Kirk \& Farrell, 1987; Eriksson et al., 1990; Gold \& Alic, 1993). In contrast, Dichomitus squalens produces MnP and laccase but not LiP (Périé \& Gold, 1991; Hatakka, 1994; Périé et al., 1996). In P. chrysosporium, lignin degradation is a secondary metabolic function elicited by starvation for carbon or nitrogen (Kirk et al., 1978; Kirk \& Farrell, 1987). In contrast, $D$. squalens degrades lignin and produces $\mathrm{MnP}$ under nitrogen-sufficient conditions, but only in the presence of $\mathrm{Mn}^{2+}$ (Périé \& Gold, 1991; Périé et al., 1996).

Recent studies have demonstrated that $P$. chrysosporium is able to degrade many chlorinated aromatic pollutants, including di, tri- and pentachlorophenols, chlorinated dibenzodioxins and chlorinated phenoxyacetic acids, and that $\mathrm{LiP}$ and $\mathrm{MnP}$ are involved in the initial degradative steps (Bumpus \& Aust, 1987; Hammel, 1989; Ryan \& Bumpus, 1989; Valli \& Gold, 1991; Valli et al., 1992; Yadav \& Reddy, 1992, 1993; Joshi \& Gold, 1993). Several intracellular enzymes from $P$. chrysosporium mycelial extracts, including a quinone reductase and a ring-opening dioxygenase, have also been purified and characterized (Rieble et al., 1994; Brock et al., 1995; Brock \& Gold, 1996). Both the quinone reductase and the dioxygenase presumably are also involved in lignin and pollutant degradation. In the work reported here we examined the mineralization of $2,4,5-\left[{ }^{14} \mathrm{C}\right] \mathrm{T}$ by $D$. squalens and re-examined its mineralization by $P$. chrysosporium. Both of these fungi degrade lignin, but they produce different complements of extracellular oxidases and peroxidases (Périé \& Gold, 1991; Périé et al., 1996); therefore, it was of interest to compare their degradative activity on chlorinated compounds. In addition, we examined the initial steps in the $D$. squalens degradative pathways for 4chlorophenoxyacetic acid (4-C), 2,4-D and 2,4,5-T.

\section{METHODS}

Chemicals. 4-Chlorophenol (4-CP), 2,4-dichlorophenol (2,4DCP) and 2,4,5-trichlorophenol (2,4,5-TCP) were obtained from Aldrich and purified by recrystallization before use. $\beta$ Xylosidase from Aspergillus niger was obtained from Sigma. U- ${ }^{14} \mathrm{C}$-Ring-labelled 2,4,5-TCP $\left(20 \mathrm{mCi} \mathrm{mmol}^{-1} ; 7 \cdot 4 \times 10^{8} \mathrm{~Bq}\right.$ $\left.\mathrm{mmol}^{-1}\right)$ was obtained from Sigma. $\left[1{ }^{14} \mathrm{C}\right]$ Bromoacetic acid $\left(25.1 \mathrm{mCi} \mathrm{mmol}^{-1} ; 9.3 \times 10^{8} \mathrm{~Bq} \mathrm{mmol}^{-1}\right)$ was obtained from Amersham.

$1-{ }^{14} \mathrm{C}$-Side-chain-labelled $2,4,5$ - $\mathrm{T}$ was prepared by the condensation of $2,4,5-\mathrm{TCP}$ with $\left[1-{ }^{14} \mathrm{C}\right]$ bromoacetic acid in the presence of sodium hydroxide as described by Furniss et al. (1989). U- ${ }^{14} \mathrm{C}-\mathrm{R}$ ing-labelled $2,4,5-\mathrm{T}$ was prepared by the condensation of ${ }^{14} \mathrm{C}$-ring-labelled 2,4,5-TCP with unlabelled bromoacetic acid as described by Furniss et al. (1989). The labelled substrates were purified by preparative silical gel TLC using methanol $(30 \%)$ and acetic acid $(1 \%)$ in ethyl acetate $(69 \%)$ as the eluent $\left(R_{F} 0 \cdot 4\right)$.

Culture conditions. Stock cultures of $P$. chrysosporium (OGC101) (Alic et al., 1987) and D. squalens (Karst Reid) (CBS 432.34) (Périé \& Gold, 1991) were maintained on slants as described previously (Alic et al., 1987; Périé \& Gold, 1991). Liquid cultures were grown from a conidial inoculum at $38^{\circ} \mathrm{C}$ (P. chrysosporium) or from a mycelial inoculum at $28^{\circ} \mathrm{C}(D$. squalens $)$ in stationary culture $(25 \mathrm{ml} ; 250 \mathrm{ml}$ flask) as described previously (Alic et al., 1987; Périé \& Gold, 1991). The medium, described previously (Kirk et al., 1978; Périé \& Gold, 1991), was supplemented with $2 \%$ glucose and either $1.2 \mathrm{mM}$ or $12 \mathrm{mM}$ ammonium tartrate, yielding high carbon-low nitrogen (HCLN) or high carbon-high nitrogen (HCHN) cultures, respectively. Cultures used for the mineralization studies were buffered with $20 \mathrm{mM}$ sodium succinate $(\mathrm{pH} \mathrm{4.5)}$. Cultures used for the metabolism of unlabelled substrates were buffered with sodium acetate ( $\mathrm{pH} 4 \cdot 5$ ). Cultures grown in the presence of $\mathrm{Mn}^{2+}$ contained a final concentration of $30 \mu \mathrm{M} \mathrm{MnSO}$. Cultures were incubated aerobically for $5 \mathrm{~d}$ ( $3 \mathrm{~d}$ for $P$. chrysosporium) after which they were purged with $99.9 \%$ oxygen every $3 \mathrm{~d}$ as described previously (Kirk et al., 1978; Périé \& Gold, 1991).

Mycelial mats from four stationary flasks were homogenized for $20 \mathrm{~s}$ in a Waring blender and used to inoculate a 2 litre flask containing 1 litre of medium supplemented with $2 \%$ glucose, $12 \mathrm{mM}$ ammonium tartrate and $20 \mathrm{mM}$ sodium succinate ( $\mathrm{pH} 4 \cdot 5$ ). Agitated cultures were grown at $28^{\circ} \mathrm{C}$ on a rotary shaker (150 r.p.m.) for 96 h (Rieble et al., 1994; Brock et al., 1995).

Preparation of enzyme extracts. Mycelial pellets were harvested by vacuum filtration using Miracloth (Calbiochem), washed in ice-cold sodium phosphate buffer ( $\mathrm{pH} 7 \cdot 0,20 \mathrm{mM}$ ) and stored at $-80^{\circ} \mathrm{C}$. All subsequent steps were carried out at $4{ }^{\circ} \mathrm{C}$. Routinely, $2 \mathrm{~g}$ wet weight of cells were broken by grinding with $5 \mathrm{~g}$ sand in a mortar and pestle in $20 \mathrm{ml} 200 \mathrm{mM}$ sodium phosphate buffer $(\mathrm{pH} 7 \cdot 0)$. The homogenate was centrifuged at $10000 \mathrm{~g}$ for $20 \mathrm{~min}$. The supernatant was recentrifuged at $150000 \mathrm{~g}$ for $60 \mathrm{~min}$, yielding a clarified cellfree extract.

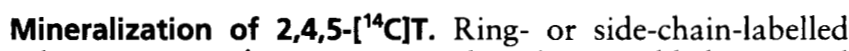
substrate $\left(3 \times 10^{4}\right.$ c.p.m. $)$ in methanol was added to $25 \mathrm{ml}$ stationary cultures after incubation for $5 \mathrm{~d}$ (D. squalens) or $3 \mathrm{~d}$ $(P$. chrysosporium). Flasks were fitted with ports which allowed periodic purging with oxygen and trapping of evolved ${ }^{14} \mathrm{CO}_{2}$ in a basic scintillation cocktail as described previously (Périé \& Gold, 1991; Joshi \& Gold, 1993) using a Beckman LS-6500 scintillation counter. The experiments were carried out in triplicate and the mean of the three determinations was plotted. ${ }^{14} \mathrm{CO}_{2}$ trapping efficiency after purging for $15 \mathrm{~min}$ was greater than $98 \%$. Counting efficiency $(>70 \%)$ was monitored with an automatic external standard.

Metabolism of unlabelled substrates. After $8 \mathrm{~d}$ incubation, the substrates in dimethyl formamide $(50 \mu \mathrm{l})$ were added to $D$. squalens cultures to a final concentration of $200 \mu \mathrm{M}$. After the indicated additional intervals, the culture medium was acidified with $\mathrm{HCl}$ and saturated with sodium chloride. The products were reduced with sodium dithionite. Ethyl acetate $(25 \mathrm{ml})$ was added, the mixture was homogenized in a blender and the organic layer was separated. The aqueous fraction was re-extracted with ethyl acetate $(3 \times 50 \mathrm{ml})$. The combined organic fraction was dried over anhydrous sodium sulfate and evaporated under reduced pressure. The products were derivatized with either acetic anhydride/pyridine $(2: 1)$ or bis $(N, O$-trimethylsilyl)trifluoro-acetamide/pyridine $\quad(2: 1)$ and analysed by GC or GC-MS (Joshi \& Gold, 1993). Quinones were identified as described previously (Joshi \& Gold, 1993). Xyloside conjugates of chlorinated phenols were also analysed directly by HPLC and by direct insertion probe MS prior to derivatization. Experiments with each substrate were carried out in triplicate with essentially identical results.

Enzymic hydrolysis of 2,4-dichlorophenol xyloside. The assay mixture $(1 \mathrm{ml})$, containing $100 \mathrm{mM}$ acetate buffer $(\mathrm{pH} \mathrm{6.5)}, \beta$ - 
xylosidase (0.5 U) and 2,4-dichlorophenol xyloside $(100 \mu \mathrm{M})$, was incubated at $27^{\circ} \mathrm{C}$ for $1 \mathrm{~h}$. The reaction mixture was extracted with ethyl acetate and the DCP produced was monitored by HPLC. For the analysis of xylose as a product, the assay was carried out at $\mathrm{pH} 7 \cdot 2$ for $24 \mathrm{~h}$. The reaction mixture was filtered using an Acrodisc (Gelman Sciences) $(0.2 \mu \mathrm{m})$ to remove insoluble protein after which excess sodium borohydride $(500 \mu \mathrm{M})$ and $\mathrm{NaOH}(1 \mathrm{mM})$ were added and the mixture was stirred for $24 \mathrm{~h}$ at room temperature (Chaplin, 1986). Water was removed under reduced pressure and the xylitol produced was derivatized with acetic anhydride/pyridine $(2: 1)$. Analysis by GC-MS was performed in comparison with a standard.

Chromatography and spectrometry. GC-MS was performed at $70 \mathrm{eV}$ on a VG Analytical $7070 \mathrm{E}$ mass spectrometer fitted with an HP 5790A gas chromatograph and a $30 \mathrm{~m}$ fused Silica column (DB-5, J \& W Scientific). The oven temperature was programmed from $70^{\circ} \mathrm{C}$ to $320^{\circ} \mathrm{C}$ at $10^{\circ} \mathrm{C} \mathrm{min}^{-1}$. Xylitol acetates were analysed using a $30 \mathrm{~m}$ Carbowax column (Altech). The oven temperature was programmed from $100^{\circ} \mathrm{C}$ to $220^{\circ} \mathrm{C}$ at $10^{\circ} \mathrm{C} \mathrm{min}{ }^{-1}$. The reaction products were also analysed by HPLC with an HP Lichrospher 100 RP8 column, using a linear gradient of $0-75 \%$ acetonitrile in $0.05 \%$ phosphoric acid over $15 \mathrm{~min}$ with a flow rate of $1 \mathrm{ml} \mathrm{min}$. Products were detected at $285 \mathrm{~nm}$. Yields on HPLC were obtained by using calibration curves obtained with standards. Preparative silica gel TLC was carried out using methanol $(10 \%)$ and acetic acid $(1 \%)$ in ethyl acetate as the eluent.

\section{RESULTS}

\section{Mineralization of $2,4,5-\left[{ }^{14} \mathrm{C}\right] T$ by $D$. squalens}

A time course for $2,4,5-\left[{ }^{14} \mathrm{C}\right] \mathrm{T}$ mineralization by HCHN-grown cultures of D. squalens is shown in Fig. 1 . Over the $31 \mathrm{~d}$ course of the experiment, approximately

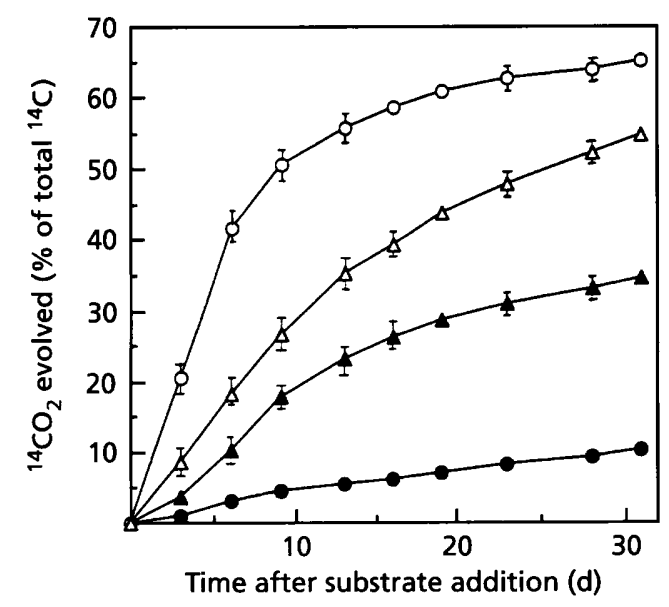

Fig. 1. Effect of $\mathrm{Mn}^{2+}$ on the mineralization of side-chain- and ring-labelled $\left[{ }^{14} \mathrm{C}\right] 2,4,5-T$ by $D$. squalens. Stationary cultures were grown at $28{ }^{\circ} \mathrm{C}$ under nitrogen-sufficient conditions in the presence and absence of $30 \mu \mathrm{M} \mathrm{Mn}{ }^{2+}$. After $5 \mathrm{~d}$ incubation, side-chain-labelled 2,4,5-T $(O, \triangle)$ or ring-labelled 2,4,5-T (0. $\Delta$ ) was added to cells grown in the absence $(0,0)$ or presence $(\triangle, \Delta)$ of $30 \mu \mathrm{M} \mathrm{Mn}{ }^{2+}$. Flasks were purged with $\mathrm{O}_{2}$ at intervals and the evolved ${ }^{14} \mathrm{CO}_{2}$ was trapped and counted as described in the text. Experiments were carried out in triplicate; error bars indicate the variance among the samples.

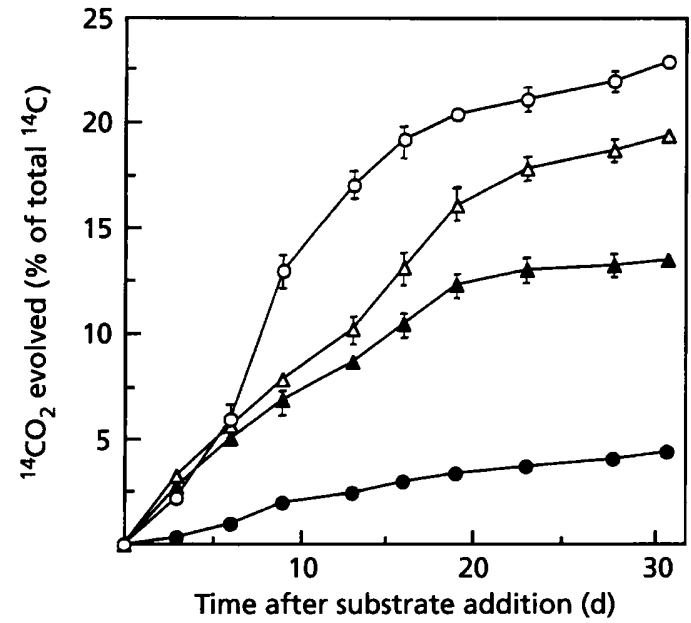

Fig. 2. Effect of nutrient nitrogen concentration on the mineralization of ring-labelled and side-chain-labelled $\left[{ }^{14} \mathrm{C}\right] 2,4,5-\mathrm{T}$ by $P$. chrysosporium. Stationary cultures were grown at $38^{\circ} \mathrm{C}$ in medium containing $1.2 \mathrm{mM}(\triangle, \Delta)$ or $12 \mathrm{mM}(0,0)$ ammonium tartrate. After $3 \mathrm{~d}$, side-chain-labelled $(0, \triangle)$ or ring-labelled $(\boldsymbol{O}, \boldsymbol{A})$ 2,4,5-T was added. Flasks were purged with $\mathrm{O}_{2}$ at intervals, and the evolved ${ }^{14} \mathrm{CO}_{2}$ was trapped and counted as described in the text. Experiments were carried out in triplicate; error bars indicate the variance among samples.

$65 \%$ of the side-chain-labelled substrate was converted to ${ }^{14} \mathrm{CO}_{2}$ in $\mathrm{Mn}^{2+}$-deficient cultures, whereas $54 \%$ of the side-chain-labelled substrate was converted in $\mathrm{Mn}^{2+}$-supplemented cultures. In contrast, $32 \%$ of the ring-labelled substrate was degraded to ${ }^{14} \mathrm{CO}_{2}$ in $\mathrm{Mn}^{2+}$-supplemented cultures, whereas only $8 \%$ of the ring-labelled substrate was converted to ${ }^{14} \mathrm{CO}_{2}$ In $\mathrm{Mn}^{2+}$-deficient cultures.

\section{Mineralization of $2,4,5-\left[{ }^{14} \mathrm{C}\right] \mathrm{T}$ by $\boldsymbol{P}$. chrysosporium}

A time course for the mineralization of $2,4,5-\left[{ }^{14} \mathrm{C}\right]$ by $P$. chrysosporium is shown in Fig. 2. Approximately $22 \%$ and $19 \%$ of the side-chain-labelled substrate was converted to ${ }^{14} \mathrm{CO}_{2}$ after $31 \mathrm{~d}$ incubation in $\mathrm{HCHN}$ and HCLN cultures, respectively. In contrast, approximately $13 \%$ and $4 \%$ of the ring-labelled substrate was converted to ${ }^{14} \mathrm{CO}_{2}$ in HCLN and $\mathrm{HCHN}$ cultures, respectively. Thus, a significant nitrogen depletion effect was detected only for the mineralization of the ringlabelled substrate.

\section{Intermediates in the metabolism of chlorophenoxyacetic acids by $D$. squalens}

Two products were formed during the metabolism of 2,4-D, as detected by HPLC analysis. The major metabolite exhibited a retention time of $8.8 \mathrm{~min}$, whereas the 2,4-DCP standard and the minor product exhibited a retention time of $11.4 \mathrm{~min}$. GC-MS analysis identified this minor product as 2,4-DCP (Table 1). GCMS analysis after reduction and acetylation of products also revealed the presence of the dechlorination product 
Table 1. Mass spectra of chlorophenoxyacetic acid metabolites, their derivatives and cleavage products

Products were identified from metabolism of 4-C, 2,4-D and 2,4,5-T by D. squalens. Cultures were incubated and extracted, and products were analysed as described in the text. The retention times and mass spectra of standard compounds were essentially identical to those of metabolites. Xylosides were analysed by direct insertion probe MS.

\begin{tabular}{|c|c|c|c|}
\hline \multirow[t]{2}{*}{ Substrate or metabolite } & \multicolumn{2}{|c|}{$\begin{array}{l}\text { Retention time } \\
(\min )\end{array}$} & \multirow[t]{2}{*}{ Mass spectrum $m / z$ (relative intensity) } \\
\hline & HPLC & GC & \\
\hline 4-Chloroacetoxybenzene & - & $4 \cdot 8$ & $\begin{array}{l}172(2 \cdot 2), 170(5 \cdot 0), 131(1 \cdot 9), 130(29 \cdot 7), 128(100 \cdot 0), 113(1 \cdot 1), 111(3 \cdot 3), \\
102(2 \cdot 3), 101(8 \cdot 6), 100(10), 99(28 \cdot 3), 75(9 \cdot 2), 73(24 \cdot 1), 65(17 \cdot 2), 63 \\
(31 \cdot 5)\end{array}$ \\
\hline 4-Chlorophenol xyloside & $8 \cdot 1$ & - & $\begin{array}{l}262(0 \cdot 3), 260(1 \cdot 2), 241(0 \cdot 8), 223(0 \cdot 8), 170(1 \cdot 2), 164(3 \cdot 1), 162(3 \cdot 8), \\
136(3 \cdot 1), 130(41 \cdot 1), 128(100), 123(1 \cdot 6), 115(5 \cdot 9), 111(10 \cdot 6), 99(14 \cdot 3), \\
85(13 \cdot 8), 77(10 \cdot 0), 75(18 \cdot 6), 73(99 \cdot 9), 71(11 \cdot 0)\end{array}$ \\
\hline 2,4-Dichlorophenol xyloside & $8 \cdot 8$ & - & $\begin{array}{l}298(0 \cdot 2), 296(1 \cdot 0), 294(1 \cdot 6), 186(1 \cdot 8), 166(10 \cdot 6), 164(65 \cdot 8), 162(100) \text {, } \\
145(2 \cdot 5), 135(3), 133(9 \cdot 3), 115(8 \cdot 8), 111(3 \cdot 3), 99(4 \cdot 3)\end{array}$ \\
\hline 2,4,5-Trichlorophenol xyloside & $9 \cdot 5$ & - & $\begin{array}{c}332(0 \cdot 2), 330(0 \cdot 4), 328(0 \cdot 5), 225(1 \cdot 2), 202(2 \cdot 9), 200(25 \cdot 9), 198(69 \cdot 5), \\
196(77 \cdot 8), 171(2 \cdot 3), 169(6 \cdot 9), 167(7 \cdot 1), 133(18 \cdot 2), 85(24 \cdot 1), 73(100)\end{array}$ \\
\hline Xylitol penta-acetate & - & $12 \cdot 2$ & $\begin{array}{l}217(13 \cdot 0), 187(13 \cdot 3), 158(12 \cdot 7), 145(46 \cdot 8), 128(11 \cdot 2), 116(24 \cdot 0), 115 \\
\quad(100), 103(72 \cdot 0), 98(25 \cdot 8), 86(20 \cdot 0), 85(54 \cdot 1), 73(33 \cdot 8)\end{array}$ \\
\hline
\end{tabular}

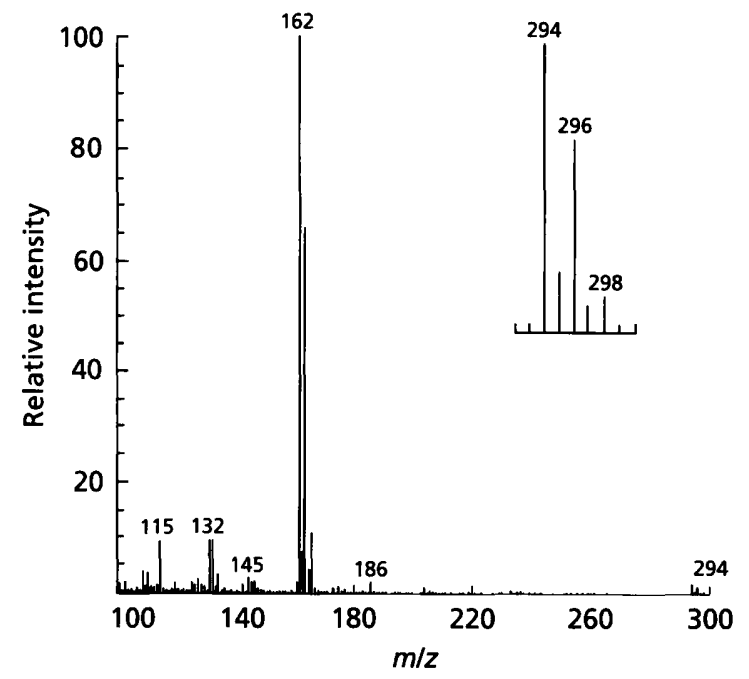

Fig. 3. Direct insertion mass spectrum of 2,4-dichlorophenol xyloside. The product was extracted from cultures and purified as described in the text. The spectrum of the molecular ion region is shown on an expanded scale.

2-chloro- $p$-benzoquinone. The major metabolite was not detected by GC-MS as its acetyl or TMS derivative. This metabolite was purified by preparative TLC $\left(R_{F} 0.4\right)$ using methanol $(30 \%)$ and acetic acid $(1 \%)$ in $69 \%$ ethyl acetate. Direct insertion probe MS of the unknown compound indicated a molecular mass of 294 $\left(\mathrm{M}^{+}\right)$and a strong fragment ion at $\mathrm{m} / z 162\left(\mathrm{M}^{+}-132\right)$ corresponding to 2,4-DCP. This suggests the molecular formula $\left(\mathrm{C}_{5} \mathrm{O}_{5} \mathrm{H}_{10}-\mathrm{H}_{2} \mathrm{O}\right)$ for the lost fragment. Thus, the parent compound is likely to be a monopentose conjugate of 2,4-DCP as confirmed below (Fig. 3; Table 1).

A sample $(0.5 \mathrm{mg})$ of this pure major metabolite was hydrolysed in $0.01 \mathrm{M} \mathrm{HCl}$ at $90^{\circ} \mathrm{C}$ for $15 \mathrm{~min}$. The reaction mixture was cooled and extracted with ethyl acetate. HPLC analysis demonstrated the formation of 2,4-DCP (retention time $11.4 \mathrm{~min}$ ). After acid hydrolysis of the metabolite as described above, water was removed under reduced pressure; the crude product mixture was reduced with sodium borohydride over $24 \mathrm{~h}$, derivatized with acetic anhydride/pyridine (2:1), and analysed by GC-MS on a Carbowax column. The mass spectrum of the major product was identical to that of authentic xylitol acetate (Table 1), indicating that the original metabolite was xylose-conjugated chlorophenol (DCPX). Enzymic hydrolysis of the DCPX with $\beta$ xylosidase yielded 2,4-DCP quantitatively, as determined by HPLC. GC-MS analysis of the exhaustively reduced and acetylated enzymic hydrolysate yielded xylitol acetate as the only sugar derivative (Table 1). This indicates that the sugar is linked to the phenolic group of the aromatic moiety via a $\beta$-glycosidic bond. The DCPX structure is shown in Fig. 6. Enzymic hydrolysis of 2,4-DCPX, using the clarified crude extract from $D$. squalens mycelia, also resulted in the formation of 2,4-DCP and xylose, suggesting that a $\beta$-xylosidase is produced by these cells. Furthermore, $24 \mathrm{~h}$ after the addition of DCPX to cultures of D. squalens, 2,4-DCP was detected in the culture medium. The structures of the 4-chlorophenol xyloside and the 2,4,5trichlorophenol xyloside were determined in a similar manner (Table 1). 


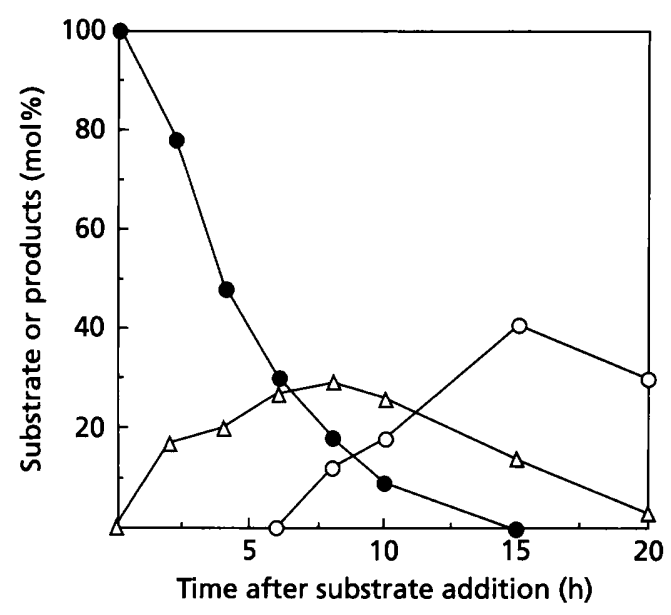

Fig. 4. Time course for the conversion of 4-C to 4-CP and 4-CPX by $D$. squalens. Cultures were grown in nitrogen-sufficient medium containing $30 \mu \mathrm{M} \mathrm{Mn}^{2+}$ for $8 \mathrm{~d}$ after which 4-C was added. At the indicated times, cultures were harvested, extracted and analysed by HPLC for 4-C $(0), 4-C P(\triangle)$ and 4-CPX $(O)$, as described in the text. The experiments were conducted in triplicate; results were very similar.

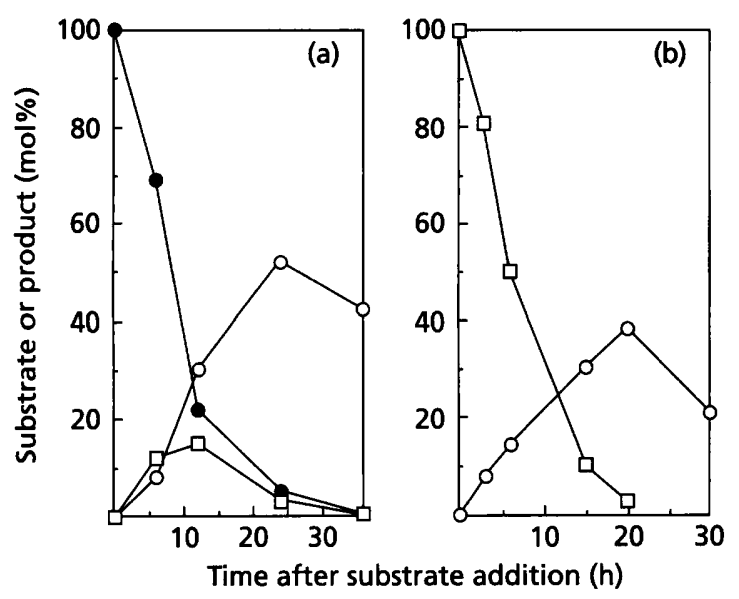

Fig. 5. Time courses for the metabolism of 2,4-D and 2,4-DCP by $D$. squalens. Cultures were grown in nitrogen-sufficient medium containing $30 \mu \mathrm{M} \mathrm{Mn}^{2+}$. (a) After $8 \mathrm{~d}$ of growth, 2,4-D was added and the disappearance of the substrate $(O)$ and the appearance of 2,4-DCPX $(O)$ and 2,4-DCP $(\square)$ were monitored. (b) After $8 \mathrm{~d}$ of growth, 2,4-DCP was added and the disappearance of the substrate $(\square)$ and the appearance of 2,4$\mathrm{DCPX}(\mathrm{O})$ were monitored. Substrates and products were extracted and monitored by HPLC as described in the text. The experiments were conducted in triplicate; results were very similar.

\section{Time courses for the metabolism of chlorophenoxyacetic acids}

(i) 4-Chlorophenoxyacetic acid. A time course for the conversion of $4-C$ by D. squalens is shown in Fig. 4 . When the substrate was added to 8-d-old cultures, it was consumed within approximately $15 \mathrm{~h}$. The 4-CP metabolite peak reached a maximum of approximately $30 \%$ yield in $8 \mathrm{~h}$, after which it declined slowly. A second metabolite, 4-chlorophenol xyloside (4-CPX) (Table 1), was detected only after $8 \mathrm{~h}$, reaching a maximum of $40 \%$ yield after $15 \mathrm{~h}$, and then declining. The time course for the appearance and disappearance of these two metabolites suggests a precursor-product relationship between 4-CP and 4-CPX.

(ii) 2,4-Dichlorophenoxyacetic and 2,4,5-trichlorophenoxyacetic acids. A time course for the conversion of 2,4-D by $D$. squalens is shown in Fig. 5(a). When the substrate was added to 8-d-old cultures, it was consumed within approximately $36 \mathrm{~h}$. 2,4-DCP was the first product observed reaching a maximum of $13 \%$ yield after $12 \mathrm{~h}$. As the level of 2,4-DCP declined, 2,4-DCPX was formed, the latter reaching a maximum of $54 \%$ yield after $25 \mathrm{~h}$. Similar results were obtained with 2,4,5-T (Table 1).

The possible precursor-product relationship between the chlorophenol and the chlorophenol xyloside intermediates was tested in a direct experiment. A time course for the conversion of 2,4-DCP to the DCPxyloside by $D$. squalens is shown in Fig. $5(\mathrm{~b})$. When 2,4-DCP was added to 8-d-old HCHN cultures, the substrate was consumed in $20 \mathrm{~h}$. The major metabolite detected was 2,4-DCPX, which reached a maximum of $40 \%$ yield after $20 \mathrm{~h}$, after which it slowly declined.

\section{DISCUSSION}

The main pathway reported for bacterial degradation of 2,4-D involves an initial ether cleavage followed by oxidative dechlorination of the resulting dichlorophenol and ortho cleavage of the aromatic ring (Sinton et al., 1986). Variations on this pathway, involving an initial reductive dechlorination followed by ether cleavage, also have been reported (Sinton et al., 1986). In the bacterium Alcaligenes eutrophus, the enzyme catalysing the initial ether cleavage has been identified as a 2,4dichlorophenoxyacetate/ $\alpha$-ketoglutarate dioxygenase (Fukumori \& Hausinger, 1993). Although mineralization of chlorophenoxyacetic acids has been reported in P. chrysosporium (Ryan \& Bumpus, 1989; Yadav \& Reddy, 1992), little has been reported on the degradation pathway. The degradation of chlorophenoxyacetic acids has not been reported previously in $D$. squalens.

Under ligninolytic conditions, $P$. chrysosporium secretes two ligninolytic peroxidases, $\mathrm{LiP}$ and $\mathrm{MnP}$ (Buswell \& Odier, 1987; Kirk \& Farrell, 1987; Gold \& Alic, 1993). In contrast, D. squalens, a lignin-degrading fungus, produces MnP and a laccase, but no LiP (Périé \& Gold, 1991; Hatakka, 1994; Périé et al., 1996). D. squalens degrades lignin and produces $\mathrm{MnP}$ under nitrogensufficient conditions, but only in the presence of $\mathrm{Mn}^{2+}$ (Périé \& Gold, 1991; Périé et al., 1996).

There has been disagreement concerning the involvement of the lignin-degrading system in the degradation of chlorinated phenoxyacetic acids by $P$. chrysosporium (Ryan \& Bumpus, 1989; Yadav \& Reddy, 1992). Furthermore, the pathway for the initial steps in 
degradation of these pollutants by white-rot fungi has not been reported previously.

Our results demonstrate that $D$. squalens extensively mineralizes 2,4,5-T under nitrogen-sufficient conditions. Mineralization also occurs under low nitrogen conditions, although to a lesser extent (data not shown). We have examined the degradation of both side-chainand ring-labelled $2,4,5-T$ by $D$. squalens. In cultures grown in the absence of $\mathrm{Mn}^{2+}$, approximately $65 \%$ of side-chain-labelled 2,4,5-T is converted to ${ }^{14} \mathrm{CO}_{2}$ during the 31-day incubation period. In cultures grown in the presence of $30 \mu \mathrm{M} \mathrm{Mn}{ }^{2+}$, approximately $54 \%$ of the 2,4,5-T is mineralized (Fig. 1). In light of our previous results on lignin degradation by $D$. squalens in the presence and absence of $\mathrm{Mn}^{2+}$ (Périé \& Gold, 1991), these experiments suggest that the ligninolytic system is not involved in the initial cleavage of this chlorophenoxyacetic acid to its chlorophenol, nor is it involved in the subsequent metabolism of the side-chain intermediate. In contrast to the results obtained with side-chain-labelled 2,4,5-T, approximately $32 \%$ of the ring-labelled substrate is degraded to ${ }^{14} \mathrm{CO}_{2}$ when cultures are grown in the presence of $\mathrm{Mn}^{2+}$, but only $8 \%$ is degraded to ${ }^{14} \mathrm{CO}_{2}$ in cultures grown in the abence of $\mathrm{Mn}^{2+}$ (Fig. 1). These results suggest the involvement of $\mathrm{MnP}$ in the degradation of the chlorinated aromatic ring, as previously reported for P. chrysosporium (Valli \& Gold, 1991; Joshi \& Gold, 1993).

Both side-chain- and ring-labelled 2,4,5-T are degraded less efficiently by $P$. chrysosporium than by $D$. squalens (Fig. 2). Only $22 \%$ of the side-chain-labelled $2,4,5-\mathrm{T}$ is degraded by $P$. chrysosporium during the course of the experiment, compared to $65 \%$ by D. squalens. Likewise, with the ring-labelled substrate, only $13 \%$ is mineralized by $P$. chrysosporium, compared to $32 \%$ by $D$. squalens. It has been well established that the lignin-degrading system of $P$. chrysosporium is repressed in cultures grown under high nitrogen conditions (Kirk et al., 1978; Kirk \& Farrell, 1987; Gold \& Alic, 1993). With sidechain-labelled 2,4,5-T, the extent of mineralization by $P$. chrysosporium is slightly greater in cultures grown in high nitrogen medium, suggesting that, as with $D$. squalens, the presumed initial cleavage of $2,4,5-\mathrm{T}$ and subsequent degradation of the side-chain intermediate are not catalysed by the lignin-degrading system. In contrast, with ring-labelled substrate, the degradation rate is considerably greater in cultures grown under nitrogen-limiting conditions, suggesting that the degradation of the ring-labelled chlorophenol intermediates occurs under conditions of nitrogen depletion. We have shown previously that 2,4-DCP and 2,4,5-TCP are degraded by $P$. chrysosporium under nitrogen-limiting conditions (Valli \& Gold, 1991; Joshi \& Gold, 1993). These results suggest the involvement of ligninolytic enzymes in the degradation of the chlorinated phenolic intermediates, in agreement with results reported by Ryan \& Bumpus (1989). Our results are also consistent with the results of Yadav \& Reddy (1992) on the degradation of side-chain-labelled 2,4,5-T. However, Yadav \& Reddy (1993) also reported that ring-labelled
2,4-D degradation by P. chrysosporium occurred more rapidly in cultures grown in high nitrogen. The latter results are inconsistent with those of Ryan \& Bumpus (1989) and with our current and previous results (Valli \& Gold, 1991; Joshi \& Gold, 1993). Although this inconsistency could be due to differences among $P$. chrysosporium strains, our results with side-chain- and ring-labelled 2,4,5-T clearly suggest that ligninolytic enzymes are involved in the degradation of the chlorinated phenolic intermediates, but not in the initial cleavage reaction nor in the subsequent metabolism of the side chain of the chlorophenoxyacetic acid substrate.

With D. squalens, we have identified 4-CP, 2,4-DCP and $2,4,5-\mathrm{TCP}$ as degradation intermediates from 4-C, 2,4-D and 2,4,5-T, respectively, by comparing their mass spectra and HPLC retention times with those of standards (Table 1). Presumably these intermediates are produced by cleavage of the ether linkage. In addition, the oxidative dechlorination of 2,4-DCP to form 2chloro- $p$-benzoquinone was observed. Interestingly, the xyloside conjugate of each phenol was also identified. The structure of the xyloside was established by direct insertion probe MS of the intact conjugate and by chemical and enzymic hydrolysis followed by HPLC and GC-MS identification of the resultant chlorophenol, which was produced in quantitative yield. In addition, the monosaccharide released by hydrolysis with $\beta$ xylosidase was identified as its xylitol penta-acetate after exhaustive reduction and acetylation, followed by GC-MS analysis (Table 1). Xylose is probably linked to the phenol by a $\beta$-glycosidic bond, because the conjugate is hydrolysed quantitative by $\beta$-xylosidase. The xylosylation of vanillyl alcohol and methyl guaiacol by the white-rot fungus Trametes versicolor also has been reported (Kondo et al., 1993). However, this is the first report of the formation of a xyloside of a chlorophenol in a wood-rotting basidiomycete. In $P$. chrysosporium chlorinated phenols undergo methylation to form their respective anisoles under secondary metabolic conditions (Lamar \& Dietrich, 1990; Valli \& Gold, 1991; Joshi \& Gold, 1993). These chlorinated anisoles would be expected to be metabolically more stable than the corresponding xylosides reported herein, and this may at least partially account for the comparatively slower rate of chlorophenoxyacetic acid metabolism exhibited by $P$. chrysosporium (Fig. 2). Under primary metabolic conditions, $P$. chrysosporium has been shown to glycosylate 9-phenanthrol (Sutherland et al., 1991). Xylosylation probably reduces the toxicity of the phenols to the fungus, allowing the conjugates to accumulate without deleterious effects. Various phenolic conjugation systems have been reported in higher eukaryotes (Mulder, 1982), and conjugation is considered to be a detoxification reaction.

The results shown in Figs 4 and 5 suggest a precursor-product relationship between the chlorophenol and the chlorophenol xyloside conjugates in D. squalens cultures degrading chlorophenoxyacetic acids. The time course for the degradation of 4-C (Fig. 4) suggests that 4-CP is the initial intermediate, which is 


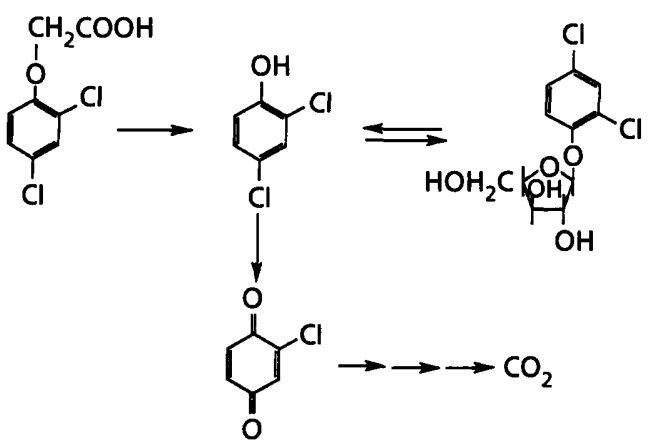

Fig. 6. Proposed pathway for the initial steps in the degradation of 2,4-D by $D$. squalens; $4-C$ and $2,4,5-T$ undergo similar reactions.

subsequently conjugated to form 4-CPX. Likewise, when 2,4-D was added to fungal cultures, the initial product produced was 2,4-DCP, and this was followed by 2,4-DCPX, suggesting that 2,4-DCP was converted to its conjugate (Fig. 5a). When 2,4-DCP was added to fungal cultures, it was rapidly converted to $2,4-\mathrm{DCPX}$, confirming that the phenol is a precursor of the conjugate 2,4-DCPX (Fig. 5b). Both fungal cultures and crude cell-free extracts cleave 2,4-DCPX to produce 2,4DCP, suggesting that the conjugate formation is reversible. All of these results suggest the pathway shown in Fig. 6 depicting the initial reactions involved in the metabolism of chlorophenoxyacetic acids. In the first step, the chlorophenoxyacetic acid is cleaved to form a chlorophenol and, possibly, a two-carbon fragment. This reaction apparently occurs during primary metabolic growth and is likely to be catalysed by an intracellular enzyme. The resulting chlorophenol is then xylosylated and the resulting conjugate is secreted. Our results also suggest that the xyloside is cleaved and the resultant phenol undergoes oxidative dechlorination primarily during secondary metabolism to produce a benzoquinone, as previously described in $P$. chrysosporium (Valli \& Gold, 1991; Joshi \& Gold, 1993).

In conclusion, our results indicate that in liquid cultures $D$. squalens mineralizes chlorinated phenoxyacetic acids more efficiently than does $P$. chrysosporium. The results also suggest the involvement of ligninolytic enzymes in the degradation of the chlorinated aromatic ring of the substrate but not in the initial side-chain cleavage reaction. In D. squalens, the chlorophenoxyacetic acids undergo ether cleavage to form corresponding chlorophenols. The chlorophenols are xylosylated in $D$. squalens to form a xylose conjugate of the phenol, whereas in $P$. chrysosporium, the chlorophenols are methylated to form their corresponding anisoles (Lamar \& Dietrich, 1990; Valli \& Gold, 1991; Joshi \& Gold, 1993). We also have shown that the xylosides are hydrolysed to regenerate chlorophenols. The latter undergo oxidative dechlorination, catalysed by manganese peroxidase, and subsequent ring cleavage (Valli \& Gold, 1991; Joshi \& Gold, 1993). We are attempting to identify the enzymes catalysing the ether cleavage, xylosylation and xyloside hydrolysis steps in this pathway.

\section{ACKNOWLEDGEMENTS}

This work was supported by the US Environmental Protection Agency (grant R-821269-01) and by the US Department of Energy, Division of Energy Biosciences (grants DE-FG0692ER20093 and DE-FG03-96ER20235). The authors thank Peter Weber, Albany Medical College, Albany, NY, USA, for useful discussions.

\section{REFERENCES}

Alic, M., Letzring, C. \& Gold, M. H. (1987). Mating system and basidiospore formation in the lignin-degrading basidiomycete Phanerochaete chrysosporium. Appl Environ Microbiol 53, 1464-1469.

Brock, B. J. \& Gold, M. H. (1996). 1,4-Benzoquinoine reductase from the basidiomycete Phanerochaete chrysosporium: spectral and kinetic analysis. Arch Biochem Biophys 331, 31-40.

Brock, B. J., Rieble, S. \& Gold, M. H. (1995). Purification and characterization of a 1,4-benzoquinone reductase from the basidiomycete Phanerochaete chrysosporium. Appl Environ Microbiol 61, 3076-3081.

Bumpus, J. A. \& Aust, S. D. (1987). Biodegradation of environmental pollutants by the white rot fungus Phanerochaete chrysosporium: involvement of the lignin-degrading system. Bioessays 6, 166-170.

Buswell, J. A. \& Odier, E. (1987). Lignin biodegradation. Crit Rev Biotechnol 6, 1-60.

Chaplin, M. F. (1986). Monosaccharides. In Carbobydrate Analysis. A Practical Approach, pp. 1-36. Edited by M. F. Chaplin \& J. F. Kennedy. Washington, DC: IRL Press.

Elo, H. A., Hervonen, H. \& Ylitalo, P. (1988). Comparative study on cerebrovascular injuries by three chlorophenoxyacetic acids (2,4-D, 2,4,5-T and MCPA). Comp Biochem Physiol C 90, 65-68.

Eriksson, K.-E. L., Blanchette, R. A. \& Ander, P. (1990). Biodegradation of lignin. In Microbial and Enzymatic Degradation of Wood and Wood Components, pp. 225-333. Edited by T. E. Timell. Berlin: Springer-Verlag.

Fukumori, F. \& Hausinger, R. P. (1993). Purification and characterization of 2,4-dichlorophenoxyacetate/ $\alpha$-ketoglutarate dioxygenase. J Biol Chem 268, 24311-24317.

Furniss, B. S., Hannaford, A. J., Smith, P. W. G. \& Tatchell, A. R. (revisors) (1989). Chapter 6. Aromatic compounds. In Vogel's Textbook of Practical Organic Chemistry, 5th edn. Essex, UK: Longman Scientific \& Technical.

Gold, M. H. \& Alic, M. A. (1993). Molecular biology of the lignindegrading basidiomycete Phanerochaete chrysosporium. Microbiol Rev 57, 605-622.

Grant, W. F. (1979). The genotoxic effects of 2,4,5-T. Mutat Res 65, 83-119.

Hammel, K. E. (1989). Organopollutant degradation by ligninolytic fungi. Enzyme Microb Technol 11, 776-777.

Hatakka, A. (1990). Lignin-modifying enzymes from selected white-rot fungi : production and role in lignin degradation. FEMS Microbiol Rev 13, 125-135.

Haugland, R. A., Schlemm, D. J., Lyons, R. P., III, Sferra, P. R. \& Chakrabarty, A. M. (1990). Degradation of the chlorinated phenoxyacetate herbicides 2,4-dichlorophenoxyacetic acid and 
2,4,5-trichlorophenoxyacetic acid by pure and mixed bacterial cultures. Appl Environ Microbiol 56, 1357-1362.

Higuchi, T. (1990). Lignin biochemistry: biosynthesis and biodegradation. Wood Sci Technol 24, 23-63.

Hileman, B. (1996). Immune system suppression linked to widely used pesticides. Chem Eng News 74, 23.

Joshi, D. K. \& Gold, M. H. (1993). Degradation of 2,4,5trichlorophenol by the lignin-degrading basidiomycete Phanerochaete chrysosporium. Appl Environ Microbiol 59, 1779-1785.

Kilbane, J. J., Chatterjee, D. K., Karns, J. S., Kellogg, S. T. \& Chakrabarty, A. M. (1982). Biodegradation of 2,4,5trichlorophenoxyacetic acid by a pure culture of Pseudomonas cepacia. Appl Environ Microbiol 44, 72-78.

Kirk, T. K. \& Farrell, R. L. (1987). Enzymatic 'combustion': the microbial degradation of lignin. Annu Rev Micribiol 41, 465-505.

Kirk, T. K., Schultz, E., Connors, W. J., Lorenz, L. F. \& Zeikus, J. G. (1978). Influence of culture parameters on lignin metabolism by Phanerochaete chrysosporium. Arch Microbiol 117, 277-285.

Kondo, R., Yamagami, H. \& Sakai, K. (1993). Xylosylation of phenolic hydroxyl group of lignin model compounds by Coriolus versicolor. Appl Environ Microbiol 59, 438-441.

Lamar, R. T. \& Dietrich, D. M. (1990). In situ depletion of pentachlorophenol from contaminated soil by Phanerochaete spp. Appl Environ Microbiol 56, 3093-3100.

Loos, M. A. (1975). Phenoxyalkanoic acids. In Herbicides: Chemistry, Degradation, and Mode of Action, vol. 1, pp. 1-128. Edited by P. C. Kearney \& D. D. Kaufman. New York: Marcel Dekker.

McCall, P. J., Vrona, S. A. \& Kelley, S. S. (1981). Fate of uniformly carbon-14 ring-labeled 2,4,5-trichlorophenoxyacetic acid and 2,4dichlorophenoxyacetic acid. J Agric Food Chem 29, 100-107.

Mulder, G. J. (1982). Conjugation of phenols. In Metabolic Basis of Detoxication: Metabolism of Functional Groups, chapter 13, pp. 247-269. Edited by W. B. Jakoby, J. R. Bend \& J. Caldwell. New York: Academic Press.

Oliveira, G. H. \& Palermo-Neto, J. (1993). Effects of 2,4dichlorophenoxyacetic acid (2,4-D) on open-field behavior and neurochemical parameters of rats. Pharmacol Toxicol 73, 79-85.

Périé, F. H. \& Gold, M. H. (1991). Manganese regulation of manganese peroxidase expression and lignin degradation by the white-rot fungus Dichomitus squalens. Appl Environ Microbiol 57, 2240-2245.
Périé, F. H., Sheng, D. \& Gold, M. H. (1996). Purification and characterization of two manganese peroxidase isozymes from the white-rot basidiomycete Dichomitus squalens. Biochim Biophys Acta 1297, 139-148.

Pieper, D. H., Reineke, W., Engesser, K.-H. \& Knackmuss, H.-J. (1988). Metabolism of 2,4-dichlorophenoxyacetic acid, 4-chloro2-methylphenoxyacetic acid and 2-methylphenoxyacetic acid by Alcaligenes eutrophus JMP 134. Arch Microbiol 150, 95-102.

Rieble, S., Joshi, D. K. \& Gold, M. H. (1994). Purification and characterization of a 1,2,4-trihydroxybenzene-1,2-dioxygenase from the basidiomycete Phanerochaete chrysosporium. J Bacteriol 176, 4838-4844.

Ryan, T. P. \& Bumpus, J. A. (1989). Biodegradation of 2,4,5trichlorophenoxyacetic acid in liquid culture and in soil by the white rot fungus Phanerochaete chrysosporium. Appl Microbiol Biotechnol 31, 302-307.

Sinton, G. L., Fan, L. T., Erickson, L. E. \& Lee, S. M. (1986). Biodegradation of 2,4-D and related xenobiotic compounds. Enzyme Microb Technol 8, 395-403.

Sutherland, J. B., Selby, A. L., Freeman, J.P., Evans, F. E. \& Cerniglia, C. E. (1991). Metabolism of phenanthrene by Phanerochaete chrysosporium. Appl Environ Microbiol 57, 3310-3316.

Valli, K. \& Gold, M. H. (1991). Degradation of 2,4-dichlorophenol by the lignin-degrading fungus Phanerochaete chrysosporium. $J$ Bacteriol 73, 345-352.

Valli, K., Wariishi, H. \& Gold, M. H. (1992). Degradation of 2,7dichlorodibenzo- $p$-dioxin by the lignin-degrading basidiomycete Phanerochaete chrysosporium. J Bacteriol 174, 2131-2137.

Yadav, J. S. \& Reddy, C. A. (1992). Non-involvement of lignin peroxidases and manganese peroxidases in 2,4,5trichlorophenoxyacetic acid degradation by Phanerochaete chrysosporium. Biotechnol Lett 14, 1089-1092.

Yadav, J. S. \& Reddy, C. A. (1993). Mineralization of 2,4dichlorophenoxyacetic acid (2,4-D) and mixtures of 2,4-D and 2,4,5-trichlorophenoxyacetic acid by Phanerochaete chrysosporium. Appl Environ Microbiol 59, 2904-2908.

Received 12 November 1996; revised 17 February 1997; accepted 19 February 1997. 